\title{
Characteristics of referrals to a mental health service for young people in care
}

\author{
Julet Butler and Panos Vostanis
}

\begin{abstract}
This paper describes the characteristics of referrals to o new direct access child mental health service for young people in the care of the local authority, during the first six months ( $n=32$ ). Consistent problems emerged within four areas: their histories within the care service ( $n=18$, $56 \%$ had had at least one more previous placement); their individual experiences of abuse $(n=23,72 \%)$ and the lack of mental health support provided to redress this; their overall poor educational status; and the psychopathology evident at the time of referral $(n=29$, 91\% had ICD-10 diagnoses, mainly mixed depressive conduct disorders).
\end{abstract}

Early work described a group of 'institution' children (Goldfarb, 1949) as displaying antisocial traits, a lack of ability to form lasting relationships, and various other traits from enuresis to 'autoerotic activities'. Since then, there has been little research on the actual mental health problems within this group. Wolkind (1974) and McCann et al (1996) have shown that the symtomatology found in early studies has not changed.

Although $80 \%$ of health authorities and health commissions in England identified services for children and adolescents with mental health problems, only $18 \%$ did so for children in the care of the local authority (National Health Service Advisory Service, 1995). One of the main problems described was getting health, educational and social services beyond the stage of 'generalised discussion' and onto joint commissioning of services for this group.

A mental health service specifically for children in care was set up in Birmingham in 1995. It aims to provide assessment and brief psychosocial interventions as well as diversion to longer-term services. It also aims to provide support and advice for staff and families working with these youngsters. This includes help for foster parents. By providing assessments on the mental health needs of these young people at the time of admission into care, it is hoped it will help other agencies involved in the young person's care plan.

\section{The study}

The service provides weekly clinics to social service residential units, varying from a shortstay assessment unit to more long-stay units. The site varies to allow access to more youngsters. It is attended by a consultant child and adolescent psychiatrist, a senior registrar, a registrar, and there is also a community psychiatric nurse attached to the clinic. Referrals are made by residential care staff and social workers.

It was decided to define the common characteristics among the referrals made. These were found to fall within four main categories: the young person's history within the care network; history of previous abuse experienced and what services had been available to them; their educational status; and their mental state findings and diagnosis.

A full history and mental state examination was completed according to Maudsley guidelines (Institute of Psychiatry \& Maudsley Hospital, 1987). ICD-10 diagnoses (World Health Organization, 1992) were made. Unfortunately, a family member was not available for history taking. which is one of the main difficulties facing the mental health team. Other information was gained from social work notes and workers at the units. Information for this study was entered on a specially constructed form. It consisted of demographic details and information relevant to the four areas described above. Thirty-two referrals were made during the first six months of the service.

\section{Findings}

Of the 32 participants, $18(56 \%)$ were male and 14 (44\%) were female. Their ages ranged from 10 to 17 years: boys between 10 and 17 years and girls between 13 and 15 years. It was a multiracial group: $69 \%$ white, 11\% Afro-Caribbean, $7 \%$ mixed White-Afro-Caribbean, $4 \%$ Asian, and 9\% mixed White-Asian. The family structures were, single-parent families $56 \%$, biological 
parent and step-parent $22 \%$, and nuclear family $19 \%$ (in one case the family structure was undefined).

\section{Social services histories}

Eight (25\%) of the adolescents were on care orders (i.e., the decision had been made by a family court), the rest were accommodated (voluntary admissions) under Section 20 of the Children's Act 1989. Fourteen (44\%) had had no more than one previous placement in care. Eighteen (56\%) had had more than one previous placement. Among the boys, this ranged from two to 20 (the next lowest being 12 placements). Among the girls, it ranged from two to eight. The placements of these youngsters varied between any combination of residential units, foster carers, and relatives. One of the boys had spent time in a secure unit, and one each of the girls and boys had been in therapeutic communities among a number of other placements.

\section{Abuse experiences}

Among the adolescents, 13 out of 14 girls, and 10 out of 18 boys had disclosed or were known to have suffered abuse before entering care. That was $72 \%$ of the overall group, not counting those who may have suffered undisclosed abuse. From the 14 girls, six (43\%) described physical abuse. five $(36 \%)$ described sexual abuse, and two (14\%) described sexual and physical abuse; and from the 18 boys, five $(28 \%)$ described physical abuse, three $(17 \%)$ described neglect, and two (11\%) described sexual and physical abuse.

When we looked at the mental health service provision which had been made available to those who had disclosed abuse, only 10 of these adolescents, i.e. seven of the girls and three of the boys, had any psychological input in the past. None were being followed-up at the time of this assessment.

\section{Educational status}

Out of 32 adolescents, 17 (53\%) were in mainstream education and eight $(25 \%)$ were in behavioural support units. Of these, nine described themselves as regular attenders, nine attended infrequently and seven did not attend school at all. A further seven were not registered with any school, despite six being within the age legally required to be in school. Nineteen youngsters $(59 \%)$ were considered below average or failing on their last school assessment. All of these were within the non-attending/poorly attending group. Only 10 of these had special educational staff input.

\section{Psychopathology}

Symptoms recorded within a standard mental state examination are described in Table 1 . Deliberate self-harm ideation and suicidality occurred in the context of depressed mood and hopelessness in all but three cases. Twenty-nine (91\%) adolescents had ICD-10 diagnoses: these consisted of all 14 girls (100\%) and $15(83 \%)$ of the boys. Most were mixed affective-conduct disorders (Table 2). Sixteen (50\%) of all adolescents interviewed had features of a depressive disorder. Twenty-seven (84\%) had features of conduct/oppositional disorder.

\section{Comments}

What emerges clearly from this study is the failure of the current system to provide stability and nurturing for often very needy children and adolescents with emotional and behavioural disturbance. Problems with the study were that it included a relatively small, service-based group, which might not necessarily be representative of all young people in care at that time. There was little informant history available, and diagnosis was predominantly made on the basis of clinical assessment. The information given on abuse experienced depended on the degree of disclosure the young person felt able to make. One could speculate that the picture is in fact a lot worse.

The aims of the service seem to fit with the characteristics found. Providing a service within the residential units will help overcome the inevitable problems which arose when these youngsters went on traditional child and adolescent unit waiting lists. Owing to the transient nature of their placements, they had often moved on by the time an appointment was available. Direct access clinics at the residential units had no waiting list, although this needs to be reviewed in the future if referrals increase. Follow-up is provided as seems necessary, even if the young person has moved from the residential unit.

Therapeutic aims are to provide brief psychosocial interventions and to 'filter' children in care through to longer-term or special services as required. By helping the young people make

Table 1. Depressive symptomatology on mental state examination $(n=32)$

\begin{tabular}{llll}
\hline & Male, $\boldsymbol{n}$ & Female, $\boldsymbol{n}$ & Total, \% \\
\hline Depressed mood & 7 & 9 & 50 \\
Hopelessness & 6 & 8 & 44 \\
Suicidality & 5 & 8 & 41 \\
Deliberate self-harm & 3 & 4 & 22 \\
ideation & & & \\
\hline
\end{tabular}


Table 2. ICD-10 diagnosis $(n=32)$

\begin{tabular}{ll}
\hline & $n(\%)$ \\
\hline Conduct disorder & $7(22)$ \\
Oppositional defiant disorder & $4(13)$ \\
Depressive conduct disorder & $9(28)$ \\
Depressive oppositional disorder & $6(19)$ \\
Major depressive disorder & $1(3)$ \\
Hyperkinetic conduct disorder & $1(3)$ \\
Pervasive developmental disorder & $1(3)$ \\
\hline
\end{tabular}

sense of their inner world and cope with their external experiences it would hopefully tackle the areas of past abuse, depressive and other psychopathology, and the effects of living one's life within the care system. Increased coping skills may improve the chance of more successful placements.

The work is also aimed at the workers within the units, the young people's families, and foster parents. Providing such support should have knock on effects for the adolescents. Residential care staff would be helped to recognise earlier those who need referral. All professionals involved in this group acknowledge the benefits of having as much insight as possible into young people's mental health needs. This service is run under joint agreement by health and social services. More systematic evaluation of the effects of this work is important, including users perceptions.

Previous research has shown that protective factors for children's psychosocial development include, temperament, supportive peer relationships, development of self-esteem, positive school experiences, and acquisition of coping skills (Quinton \& Rutter, 1985). If this is the case, positive change for these young people at risk will only occur when health, education and social services eventually formulate and implement joint policies. Further service development should rely on joint commissioning between health and local authorities. Despite the high rate of established mental health problems and the financial implications, such a service could be relatively economical, if residential care staff are trained to detect and refer the more severe cases. For this reason, training courses have been set up by the mental health team and the Birmingham Local Authority for residential care staff. These will hopefully be extended to include foster carers and social workers.

\section{References}

GOLDFARB, W. (1949) Effects of early institutional care on adolescent personality: Rorschach test differences between family reared, institution reared and schizophrenic children. American Joumal of Orthopsychiatry, 19, 624-633.

INSTITUTE OF PSYCHIATRY \& MAUDLSEY HOSPITAL (1987) Psychiatric Examination. Oxford: Oxford Medical Publications.

MCCANN, J. B.. JAmes, A., WILson, S., et al (1996) Prevalence of psychiatric disorders in young people in the care system. British Medical Journal, 313. 1529-1530.

National Health SeRvice Health AdVisORY Service (1995) Child and Adolescent Mental Health Services. London: HMSO.

GUINTON, D. \& RUTTER, M. (1985) Parenting behaviour of mothers raised in care. In Longitudinal Studies in Child Psychology and Psychiatry (Ed. A. R. Nicol). pp. 157201. Chichester: Wiley.

Wolkind, S. (1974) The components of affectionless psychopathy' in institutionalized children. Journal of Child Psychology and Psychiatry, 16, 215-220.

WORLD HEALTH ORGANIZATION (1992) The Tenth Revision of the International Classification of Diseases and Related Health Problems (ICD-10). Geneva: WHO.

Julet Butler, Senior Registrar in Child and Adolescent Psychiatry, Department of Psychological Medicine, Great Ormond Street Hospital for Children, Great Ormond Street, London WC1N 3JH; and *Panos Vostanis, Senior Lecturer in Child and Adolescent Psychiatry, University of Birmingham, Parkview Clinic, Queensbridge Road, Moseley, Birmingham B13 $8 Q E$

*Correspondence 